\title{
Analgesic and Antiinflammatory Activities of Clematis erecta Aerial Parts
}

\author{
R. CHAWLA*, D. KUMAR ${ }^{1}$, A. GODARA ${ }^{2}$, A. ARORA ${ }^{3}$, K. RANA ${ }^{3}$, S. KUMAR ${ }^{1}$, A. SHARMA AND H. JOSHI ${ }^{3}$
}

University Institute of Pharmaceutical Sciences and Research, Baba Farid University of Health Sciences, Faridkot-151 203, ${ }^{1}$ Department of Pharmaceutical Sciences and Drug Research, Punjabi University, Patiala-147 002, ${ }^{2}$ Rayat Institute of Pharmacy, Rayat-Bahra Ropar Campus, Ropar, Railmajra-144 533, ${ }^{3}$ Department of Pharmaceutical Chemistry, S.D. College of Pharmacy, Barnala-148 101, ${ }^{4}$ University Institute of Pharmaceutical Sciences, Panjab University, Chandigarh-160 014, India

Chawla, et al.: Analgesic and Antiinflammatory Activity of Clematis erecta

\begin{abstract}
Clematis erecta L. (Upright Virgin's Bower; Ranunculaceae) has been traditionally used in the treatment of insomnia, urinary irritation, ulcers, neuralgic and rheumatic pain. But no systematic pharmacological work has ever been carried out on the plant to validate its traditional claims. Thus, the present study was planned to investigate analgesic and antiinflammatory activities of $\boldsymbol{C}$. erecta aerial parts using tail immersion test and carrageenan-induced paw edema model in rats, respectively. Methanol extract was prepared after defatting plant material with petroleum ether using Soxhlet apparatus. Ethyl acetate and 1-butanol fractions from methanol extract were prepared using standardized procedure. The methanol extract, ethyl acetate and 1-butanol fractions were evaluated for analgesic and antiinflammatory activities at doses of 100,200 or $400 \mathrm{mg} / \mathrm{kg}$, p.o. Diclofenac sodium (10 mg/kg, p.o.) and indomethacin $(5 \mathrm{mg} / \mathrm{kg}$, p.o.) were used as standard analgesic and antiinflammatory drugs, respectively. The methanol extract and ethyl acetate fraction exhibited significant analgesic activity at the dose of $400 \mathrm{mg} / \mathrm{kg}$ comparable to that of the standard. The methanol extract and ethyl acetate fraction exhibited significant antiinflammatory activity at the dose of 400 $\mathrm{mg} / \mathrm{kg}$ with respect to control as it inhibited paw edema in rats to 73.17 and $78.04 \%$, respectively, during the $5 \mathrm{~h}$ of the study. Phytochemical screening of plant showed presence of triterpenoids and coumarins as major classes of phytoconstituents. Finally, it can be concluded that these phytoconstituents could be responsible for the observed analgesic and antiinflammatory activities.
\end{abstract}

Key words: Analgesic, Antiinflammatory, Clematis erecta, Ranunculaceae

Traditionally, Clematis erecta L. (Upright Virgin's Bower; Ranunculaceae) has been used in the treatment of insomnia, neuralgic, rheumatic headache, impaired memory, urinary irritation, ulcers, pain in testicles, gout, inflammatory conditions, skin, bone and reflex neuroses of women from ovarian or urinary irritation ${ }^{[1]}$. C. erecta has been reported to contain quaternary isoquinoline alkaloids, magnoflorine, corytuberine.
Despite a long tradition of use as homeopathic remedy in treating various ailments, $C$. erecta has not been

This is an open access article distributed under the terms of the Creative Commons Attribution-NonCommercial-ShareAlike 3.0 License, which allows others to remix, tweak, and build upon the work non-commercially, as long as the author is credited and the new creations are licensed under the identical terms

Accepted 21 April 2017

Revised 04 January 2017

Received 19 July 2016

Indian J Pharm Sci 2017;79(3):474-477 
investigated for any therapeutic activity. No systematic research work has been carried out on this potential plant to validate traditional claims for analgesic and antiinflammatory activities. Thus, it was planned to investigate analgesic and antiinflammatory activities of $C$. erecta aerial parts.

C. erecta aerial parts were procured from K. R. Indo German American Trading Company, Kurukshetra, Haryana, India in the month of March 2009. The identity of the plant was confirmed at the Raw material Herbarium and Museum, National Institute of Science Communication and Information Resources, New Delhi, India (Ref. No. NISCAIR/RHMD/ Consult/-2008-09/1192/224, dated 09/04/2009). The methanol extract of dried aerial parts was prepared after defatting exhaustively with petroleum ether in a Soxhlet apparatus as per standard procedure ${ }^{[2]}$. The ethyl acetate and 1-butanol fractions were prepared from methanol extract using standard reported procedure $^{[3]}$. The solvents, of LR grade used in present investigations were procured from E Merck, New Delhi, India. Solvents from extracts and fractions were recovered under reduced pressure using rotary vacuum evaporator (Perfit, Ambala). The methanol extract, ethyl acetate and 1-butanol fractions were subjected to preliminary phytochemical screening ${ }^{[4]}$.

Analgesic and antiinflammatory activities of test samples were evaluated using tail immersion test ${ }^{[2]}$ and carrageenan-induced paw edema model ${ }^{[5]}$, respectively. Diclofenac sodium (Cipla Pharmaceuticals, Baddi, Himachal Pradesh; $10 \mathrm{mg} / \mathrm{kg}$, p.o.) and indomethacin (Triko Pharmaceuticals, Rohtak, Haryana; $5 \mathrm{mg} / \mathrm{kg}$, p.o.) were used as standard analgesic and antiinflammatory drugs, respectrively. Albino rats of Wistar strain (150$200 \mathrm{~g}$ ) of either sex were used in the entire study. Normal saline was used as vehicle for preparing the suspension of various test doses. The approval was taken from Institutional Animal Ethics Committee of S.D. College of Pharmacy, Barnala before carrying out analgesic activity study (SDCP/IAEC-2009/04, dated 15-02-2009) and from Institutional Animal Ethics Committee of Pinnacle Biomedical Research Institute, Bhopal for antiinflammatory activity study (PBRI/12/ IAEC/PN-234). A total of two experimental protocols were designed to study analgesic and antiinflammatory activities of $C$. erecta aerial parts. In each experimental protocol, eleven groups were made as described follow: group 1: control group received vehicle; group 2: standard group received respective standard drug for comparison (diclofenac sodium/indomethacin); groups 3, 4 and 5: test groups received different doses of methanol extract $(100,200$ or $400 \mathrm{mg} / \mathrm{kg}$, p.o., respectively); groups 6,7 and 8: test groups received different doses of ethyl acetate fraction $(100,200$ or $400 \mathrm{mg} / \mathrm{kg}$, p.o., respectively) and groups 9, 10 and 11: test groups received different doses of 1-butanol fraction $(100,200$ or $400 \mathrm{mg} / \mathrm{kg}$, p.o., respectively). The test drugs were compared with standard drug and control by one way analysis of variance (ANOVA) followed by Student-Newman-Keul's test ${ }^{[6]}$.

The percent yield of methanol extract of $C$. erecta aerial parts was found to be $13.10 \% \mathrm{w} / \mathrm{w}$. Percent yields of ethyl acetate and 1-butanol fractions were found to be 24.58 and $14.21 \% \mathrm{w} / \mathrm{w}$ in relation to methanol extract. Phytochemical screening showed presence of triterpenoids, tannins, coumarins, saponins and carbohydrates in methanol extract; coumarins and triterpenoids in ethyl acetate fraction; and tannins and saponins in 1-butanol fraction.

The methanol extract (100, 200 or $400 \mathrm{mg} / \mathrm{kg}$, p.o.), ethyl acetate fraction $(100,200$ or $400 \mathrm{mg} / \mathrm{kg}$, p.o.), 1-butanol fraction $(100,200$ or $400 \mathrm{mg} / \mathrm{kg}$, p.o.), control (saline, p.o.) and diclofenac sodium $(10 \mathrm{mg} / \mathrm{kg}$, p.o.) were subjected to analgesic activity using tail immersion test. The test samples at different doses increased the pain threshold significantly during the period of observation and this indicates the involvement of a higher center ${ }^{[6]}$. The analgesic activity of test samples was assessed by measuring mean tail flicking reaction time and percent maximum possible effect (\%MPE). The methanol extract and ethyl acetate fraction exhibited significant activity at a dose of 400 $\mathrm{mg} / \mathrm{kg}$ as it showed significant tail flicking reaction time with respect to the control and statistically equivalent to standard drug during whole period of the study. The $\%$ MPE was observed to be at maximum level after 30 min of observation and decreased during 1 or $2 \mathrm{~h}$ of observations, which might be due to metabolism of test drug. The 1-butanol fraction exhibit mild analgesic activity as it did not significantly increase pain threshold in terms of reaction time during whole period of the study (Table 1).

The methanol extract $(100,200$ or $400 \mathrm{mg} / \mathrm{kg}$, p.o.), ethyl acetate fraction $(100,200$ or $400 \mathrm{mg} / \mathrm{kg}$, p.o.), 1-butanol fraction $(100,200$ or $400 \mathrm{mg} / \mathrm{kg}$, p.o.), control (saline, p.o.) and indomethacin $(5 \mathrm{mg} / \mathrm{kg}$, p.o.) were subjected to antiinflammatory activity using carrageenan-induced hind paw edema model. Carrageenan is the phlogistic agent used for testing 
antiinflammatory drugs for acute inflammation as it is not known to be antigenic and devoid of apparent systemic effects. This model exhibited higher degree of reproducibility and biphasic response. The first phase is mediated through the release of histamine, serotonin and kinins, whereas second phase is related to the release of prostaglandins and slow reacting substances, which peak at $3 \mathrm{~h}^{[6]}$. The tail immersion test has been used extensively to examine the effects of morphine-like compounds in animals. The test is measure of nociceptive sensitivity based on reflexive limb withdrawal from a noxious stimulus (warm water maintained at $55^{\circ}$ ). It has been established that opioid analgesics can inhibit perception and reaction to thermal nociception. Diclofenac was used as analgesic drug as it induced peripheral antinociception by participation of opioid system ${ }^{[7]}$, and central nociception through inhibiting cyclooxygenases enzymes ${ }^{[8]}$. The antiinflammatory activity of test samples was assessed by measuring mean increase in paw diameter $(\mathrm{mm})$ and percent inhibition of carrageenan-induced paw edema. The methanol extract and ethyl acetate fraction of $C$. erecta aerial parts exhibited significant antiinflammatory activity at a dose of $400 \mathrm{mg} / \mathrm{kg}$ as it inhibited paw edema in rats to 73.17 and $78.04 \%$, respectively, in comparison to standard drug, which inhibited to $83.33 \%$. The methanol extract and ethyl acetate fraction significantly decreasing the paw diameter with respect to control during whole period of the study. The 1-butanol fraction exhibit mild antiinflammatory activity at higher dose level during $3 \mathrm{~h}$ of observation as it did not increase significantly percent inhibition of paw oedema in rats with respect to standard drug (Table 2).

The phytochemical screening revealed the presence of triterpenoids and coumarins as major classes of phytoconstituents in the methanol extract and ethyl acetate fraction of $C$. erecta aerial parts. Preliminary phytochemical studies showed presence of coumarins and triterpenoids in bioactive extract and/or fraction of $C$. erecta aerial parts. The available literature reveals that a large number of coumarins-muralatins A-B and daphnetin; and triterpenoids-ursolic acid, oleanolic acid and taraxerone have been reported to exhibit analgesic and antiinflammatory activities ${ }^{[9-12]}$. In agreement to these reports, it is suggested from the

TABLE 1: ANALGESIC ACTIVITY OF C. ERECTA AERIAL PARTS USING TAIL IMMERSION TEST

\begin{tabular}{|c|c|c|c|c|c|c|c|c|}
\hline \multirow{2}{*}{$\begin{array}{l}\text { Treatment } \\
\text { group }\end{array}$} & \multirow{2}{*}{$\begin{array}{c}\text { Dose } \\
\text { (mg/kg) }\end{array}$} & \multirow{2}{*}{$\begin{array}{c}\text { Mean }^{\mathrm{n}} \text { basal } \\
\text { reading } \\
(\mathrm{sec}) \pm S D\end{array}$} & \multicolumn{3}{|c|}{ Mean ${ }^{n}$ reaction time $(\mathrm{sec}) \pm S D$} & \multicolumn{3}{|c|}{$\% M P E$} \\
\hline & & & $30 \mathrm{~min}$ & $1 \mathrm{~h}$ & $2 \mathrm{~h}$ & $30 \mathrm{~min}$ & $1 \mathrm{~h}$ & $2 \mathrm{~h}$ \\
\hline Control & Vehicle & $3.58 \pm 0.19$ & $3.80 \pm 0.11^{\mathrm{a}}$ & $3.70 \pm 0.10^{\mathrm{a}}$ & $3.65 \pm 0.15^{a}$ & 1.92 & 1.05 & 0.61 \\
\hline Diclofenac sodium & 10 & $3.40 \pm 0.15$ & $12.47 \pm 0.40^{*}$ & $10.47 \pm 0.78^{*}$ & $8.47 \pm 0.98^{*}$ & 78.19 & 60.95 & 43.71 \\
\hline \multirow{3}{*}{$\begin{array}{l}\text { Methanol } \\
\text { extract }\end{array}$} & 100 & $3.60 \pm 0.03$ & $7.58 \pm 0.08^{* a}$ & $6.50 \pm 0.01^{* a}$ & $5.87 \pm 0.14^{* a}$ & 34.91 & 25.44 & 19.91 \\
\hline & 200 & $3.75 \pm 0.04$ & $9.87 \pm 0.07^{* a}$ & $8.41 \pm 0.14^{* a}$ & $6.97 \pm 0.14^{* a}$ & 54.40 & 41.42 & 28.62 \\
\hline & 400 & $3.35 \pm 0.41$ & $11.89 \pm 0.09^{*}$ & $9.80 \pm 0.87^{*}$ & $8.01 \pm 0.17^{*}$ & 73.30 & 55.36 & 40.00 \\
\hline Ethyl acetate & 100 & $3.45 \pm 0.20$ & $7.90 \pm 0.18^{* a}$ & $6.80 \pm 0.87^{* a}$ & $5.98 \pm 0.47^{* a}$ & 38.52 & 29.01 & 21.90 \\
\hline \multirow[t]{3}{*}{ fraction } & 200 & $3.50 \pm 0.78$ & $10.11 \pm 0.14^{* a}$ & $9.90 \pm 0.88^{* a}$ & $7.05 \pm 0.80^{* a}$ & 57.48 & 55.65 & 30.81 \\
\hline & 400 & $3.51 \pm 0.45$ & $12.10 \pm 0.90^{*}$ & $10.25 \pm 0.87^{*}$ & $7.88 \pm 0.97^{*}$ & 74.76 & 58.66 & 38.09 \\
\hline & 100 & $3.52 \pm 0.04$ & $5.01 \pm 0.08^{* a}$ & $4.50 \pm 0.14^{* a}$ & $4.25 \pm 0.18^{* a}$ & 12.97 & 8.54 & 6.36 \\
\hline \multirow[t]{2}{*}{ 1-Butanol fraction } & 200 & $3.59 \pm 0.11$ & $6.10 \pm 0.24^{* a}$ & $5.42 \pm 0.50^{* a}$ & $4.85 \pm 0.19^{* a}$ & 21.99 & 16.04 & 11.04 \\
\hline & 400 & $3.60 \pm 0.15$ & $6.85 \pm 0.52 * a$ & $6.21 \pm 0.18^{* a}$ & $5.45 \pm 0.58^{* a}$ & 28.51 & 22.89 & 16.22 \\
\hline
\end{tabular}

$\mathrm{n}=6$; The data is expressed as mean $\pm \mathrm{SD}$; ${ }^{*} \mathrm{P}<0.05 \mathrm{vs}$. control; ${ }^{\mathrm{P}}<0.05$ vs. diclofenac sodium; one way ANOVA followed by Student-NewmanKeul's test

TABLE 2: ANTIINFLAMMATORY ACTIVITY OF C. ERECTA AERIAL PARTS USING CARRAGEENANINDUCED RAT PAW EDEMA MODEL

\begin{tabular}{|c|c|c|c|c|c|c|c|}
\hline \multirow{2}{*}{ Treatment } & \multirow{2}{*}{ Dose $(\mathrm{mg} / \mathrm{kg})$} & \multicolumn{3}{|c|}{ Paw diameter $(\mathrm{mm})$} & \multicolumn{3}{|c|}{ \%Inhibition } \\
\hline & & $1 \mathrm{~h}$ & $3 \mathrm{~h}$ & $5 \mathrm{~h}$ & $1 \mathrm{~h}$ & $3 \mathrm{~h}$ & $5 \mathrm{~h}$ \\
\hline Control & Vehicle & $1.64 \pm 0.10^{a}$ & $1.87 \pm 0.07^{a}$ & $2.46 \pm 0.13^{a}$ & $\cdots$ & $\cdots$ & $\cdots$ \\
\hline Indomethacin & 5 & $0.75 \pm 0.10^{*}$ & $0.65 \pm 0.09^{*}$ & $0.41 \pm 0.08^{*}$ & 54.26 & 65.24 & 83.33 \\
\hline \multirow{3}{*}{$\begin{array}{l}\text { Methanol } \\
\text { extract }\end{array}$} & 100 & $1.67 \pm 0.09^{a}$ & $1.91 \pm 0.07^{a}$ & $2.43 \pm 0.11^{\mathrm{a}}$ & 1.83 & 2.14 & 1.21 \\
\hline & 200 & $1.46 \pm 0.13^{* a}$ & $1.68 \pm 0.14^{\mathrm{a}}$ & $1.85 \pm 0.10^{* a}$ & 10.97 & 10.16 & 24.79 \\
\hline & 400 & $1.03 \pm 0.11^{*}$ & $0.85 \pm 0.12^{*}$ & $0.66 \pm 0.09 *$ & 37.20 & 54.54 & 73.17 \\
\hline \multirow{3}{*}{$\begin{array}{l}\text { Ethyl acetate } \\
\text { fraction }\end{array}$} & 100 & $1.65 \pm 0.10^{\mathrm{a}}$ & $1.88 \pm 0.07^{a}$ & $2.40 \pm 0.12^{\mathrm{a}}$ & 0.61 & 0.53 & 2.43 \\
\hline & 200 & $1.33 \pm 0.12^{* a}$ & $1.54 \pm 0.12 * a$ & $1.72 \pm 0.09 * a$ & 18.90 & 17.64 & 30.08 \\
\hline & 400 & $0.87 \pm 0.10^{*}$ & $0.73 \pm 0.11^{*}$ & $0.54 \pm 0.07^{*}$ & 46.95 & 60.96 & 78.04 \\
\hline \multirow{3}{*}{$\begin{array}{l}\text { 1-Butanol } \\
\text { fraction }\end{array}$} & 100 & $1.69 \pm 0.11^{\mathrm{a}}$ & $1.93 \pm 0.08^{a}$ & $2.45 \pm 0.11^{\mathrm{a}}$ & 3.05 & 3.20 & 0.41 \\
\hline & 200 & $1.60 \pm 0.12^{a}$ & $1.83 \pm 0.08^{a}$ & $2.23 \pm 0.05^{a}$ & 2.43 & 2.13 & 9.34 \\
\hline & 400 & $1.24 \pm 0.10^{* a}$ & $1.34 \pm 0.11^{* a}$ & $1.55 \pm 0.11^{* a}$ & 24.39 & 38.34 & 36.99 \\
\hline
\end{tabular}

$\mathrm{n}=6$; the data is expressed as mean $\pm \mathrm{SD}$; ${ }^{*} \mathrm{P}<0.05$ vs. control; ${ }^{\mathrm{P}}<0.05$ vs. indomethacin; one way ANOVA followed by Student-Newman-Keul's test 
results that analgesic and antiinflammatory activities of C. erecta aerial parts are attributed to coumarins and triterpenoids. Therefore, it can be concluded that these phytoconstituents may be responsible for analgesic and antiinflammatory activities of $C$. erecta aerial parts.

\section{Acknowledgements:}

The authors wish to acknowledge S. D. College of Pharmacy, Barnala, Punjab, India for providing necessary facilities and Dr. H. B. Singh, Scientist F, Head of Raw material Herbarium and Museum, National Institute of Science Communication and Information Resources, New Delhi, India for confirming the identity of the collected plant material.

\section{Conflict of interest:}

All authors declare no conflict of interests.

\section{Financial support:}

Nil.

\section{REFERENCES}

1. Chawla R, Kumar S, Sharma A. The genus Clematis (Ranunculaceae): Chemical and pharmacological perspectives. J Ethnopharmacol 2012;143:116-50.

2. Prakash O, Kumar D, Kumar S. Screening of methanol extract and ethyl acetate fraction of Abies webbiana Lindl. for neuropharmacological activities. Indian $\mathrm{J}$ Pharm Sci 2015;77:536-41.
3. Kumar D, Kumar S. Screening of antianxiety activity of Abies pindrow Royle aerial parts. Indian J Pharm Educ Res 2015;49:66-70.

4. Farnsworth NR. Biological and phytochemical screening of plants. J Pharm Sci 1966;55:225-76.

5. Madaan R, Kumar S. Screening of alkaloidal fraction of Conium maculatum Linn. aerial parts for analgesic and antiinflammatory activity. Indian J Pharm Sci 2012;74:457-60.

6. Scheffer WC. Statistics for the Biological Sciences. Philippines: Addison-Wesley Publishing Company; 1980. p. 121-41.

7. Silva LC, Castor MG, Navarro LC, Romero TR, Duarte ID. $\kappa$-Opioid receptor participates of NSAIDs peripheral antinociception. Neurosci Lett 2016;622:6-9.

8. Kokki H. Nonsteroidal anti-inflammatory drugs for postoperative pain: A focus on children. Paediatr Drugs 2003;5:103-23.

9. Lv HN, Wang S, Zeng KW, Li J, Guo XY, Ferreira D, Zjawiony $\mathrm{JK}$, et al. Antiinflammatory coumarin and benzocoumarin derivatives from Murraya alata. J Nat Prod 2015;78:279-85.

10. Du G, Tu H, Li X, Pei A, Chen J, Miao Z, et al. Daphnetin, a natural coumarin derivative, provides the neuroprotection against glutamate-induced toxicity in HT22 cells and ischemic brain injury. Neurochem Res 2014;39:269-75.

11. Biswas M, Biswas K, Ghosh AK, Haldar PK. A pentacyclic triterpenoid possessing analgesic and antiinflammatory activities from the fruits of Dregea volubilis. Pharmacog Mag 2009;9:315-9.

12. Vasconcelos MAL, Royo VA, Ferreira DS, Crotti AEM, Silva MLA, Carvalho JCT, et al. In vivo analgesic and antiinflammatory activities of ursolic acid and oleanolic acid from Miconia albicans (Melastomataceae). Z Naturforsch C 2006;61; 477-82. 